\title{
Um panorama nublado: a atividade musical como reconstrução identitária
}

A cloudy panorama: musical activity as identity reconstruction

Gabriel Barth da Silva

Universidade do Porto (PT)

gabrielbarths@gmail.com

Paula Guerra

Universidade do Porto (PT)

mariadeguerra@gmail.com 


\section{Resumo}

O futuro se revela como uma entidade cada vez mais nebulosa e incerta para a sociedade contemporânea. Diversos fe-nômenos contemporâneos estão na gê-nese da desesperança, no olhar limitado ao futuro, intrinsecamente modificando as formas de vivência social e de atitudes presentes. $\mathrm{Na}$ busca por esse futuro, a memória surge como uma ferramenta que, alicerçada na atividade musical, per-mite a ressignificação do presente e do passado, permitindo novos sentidos sobre o futuro. $O$ presente artigo propõe uma análise de como diversas áreas do conhe-cimento agregam nessa correlação de memória, atividade musical e sentido, e de como esse diálogo é essencial para gerar reconfigurações identitárias possíveis para construir novos horizontes sobre o futuro.

Palavras-chave: Identidades; Memória; Musical Activity.

\section{Abstract}

The future reveals itself as an increasingly nebulous and uncertain entity for contem-porary society. Several contemporary phenomena are in the genesis of hope-lessness, in the limited look to the future, intrinsically modifying the forms of social experience and present attitudes. In the search for this future, memory emerges as a tool that, based on musical activity, al-lows the re-signification of the present and the past, allowing new meanings about the future. This article proposes an analysis of how different areas of knowledge add to this correlation of memory, musical activity and meaning, and how this dialogue is essential to gen-erate possible identity reconfigurations to build new horizons about the future.

Keywords: Identities; Memory; Future; Futuro; Atividade Musical.

\footnotetext{
1 Gabriel Barth da Silva é mestrando em Sociologia pela Universidade do Porto em Portugal e graduado em Psicologia pela Pontifícia Universidade Católica do Paraná no Brasil. Atua principalmente nas temáticas da so-ciologia da arte e da música, da música popular e dos estudos culturais.

2 Paula Guerra é professora no Departamento de Sociologia da Faculdade de Letras da Universidade do Porto. É investigadora do Instituto de Sociologia da Universidade do Porto, do Centro de Estudos de Geografia e Or-denamento do Território, do CITCEM - Centro de Investigação Transdisciplinar «Cultura, Espaço e Memória» e do DINÂMIA'CET - IUL, Centro de Estudos sobre a Mudança Socioeconómica e o Território do ISCTE-IUL. É Professora Adjunta do Griffith Center for Social and Cultural Research na Austrália. Coordena e participa em vários projetos de investigação nacionais e internacionais no âmbito das culturas juvenis, da sociologia da arte, da cultura e da música. É, igualmente, supervisora de diversos projetos de mestrado, doutoramento e pós-doutoramento nas referidas disciplinas.
} 


\section{Introdução: Para onde foi o futuro?}

Para elaborar da presente reflexão sobre a crise de sentido e perspectiva, se torna necessário estruturar acerca do que compõem esses conceitos, e do que pode levar a essa crise. É possível utilizar da obra de Berger e Luckmann (1995), em que os autores defendem que o "sentido é constituído na consciência humana: na consciência do indiví-duo, que é individualizado em um corpo e quem é socializado como pessoa"3 (1995, p. 10). É percebido por Berger e Luckmann (1995) como a consciência por si só não é o su-ficiente, necessitando de um objeto para que se seja consciente, tendo um objetivo. Esse objeto é constituído de diversos elementos sintéticos da consciência, o formando pelas ferramentas da percepção, da memória ou da imaginação. O sentido seria como uma forma complexa da consciência, também não existindo de forma independente mas em referência a um ponto. Então, "o sentido é a consciência do fato que uma relação existe entre experiências"4 (BERGER \& LUCKMANN, 1995, p. 11).

A ação social, como apresentam Berger e Luckmann (1995), também compartilha dessa estrutura de sentido, porém ela pode atuar de diversas formas, como uma relação mútua ou unilateral, direta ou indireta, em relação a indivíduos presentes ou ausentes. Isso estrutura o sentido das ações de instituições sociais, principalmente àquelas que têm co-mo função principal a produção e transmissão de sentido. A crise de sentido, nesse caso, pode surgir de diversas formas, sendo um exemplo o cenário em que os indivíduos de uma sociedade não conseguem responder às condições estabelecidas de sentido dessas instituições, gerando uma discrepância entre quem "são" e quem "deveriam ser".

A presente secção possui seu nome inspirado no livro homônimo de Marc Augé (2012), que explora a transformação da consciência social após o fenômeno da globaliza-ção. O autor reitera como há uma maior consciência da fragilidade do planeta, em que ele, além de ameaçado, se apresenta "infinitamente pequeno em um universo infinita-mente grande" (2012, p. 34), isso gera uma consciência que inquieta, pois é reiterada a perspectiva que "compartilhamos um espaço reduzido que tratamos mal" (2012, p. 34). Além disso, o autor reitera a tomada de consciência no aumento da distância social entre os mais ricos e os mais pobres, além da oposição de países desenvolvidos e subdesenvol-vidos. Como Augé explicita: "a consciência planetária como consciência ecológica e so-cial é, assim, uma consciência infeliz" (2012, p. 34).

É percebido por Augé (2012) como há então uma relação entre a história e o futu-ro. O autor ressalta como a história "até um passado relativamente recente, foi escrita do ponto de vista do futuro, em função do que seria ou deveria ser o futuro: restauração, progresso ou revolução" (2012, p. 81), porém, a mudança do século gerou um esgota-mento das esperanças e das ilusões. Há então o "fim das grandes narrativas acerca do fu-turo" (2012, p. 93), sem perspectiva sobre os grandes progressos da humanidade.

\footnotetext{
3 Tradução livre de: "Meaning is constituted in human consciousness: in the consciousness of the individual, who is individuated in a body and who has been socialized as a person".

4 Tradução livre de: "Meaning is consciousness of the fact that a relationship exists between experiences".
} 
Outro problema social que gera essa crise de sentido, ressaltado por Berger e Luckmann (1995), diz respeito a sociedades cujos valores sociais não possuem concor-dância perante seus membros, não trazendo igualdade. Isso ocorre principalmente em sociedades industrializadas, em que os sistemas de valor e o sentido oferecido não são uma propriedade comum aos seus membros.

É explorado por Candau (2019) como, nas sociedades contemporâneas, "as estru-turas a memorizar e as estruturas de recordação coletiva se tornariam muito vagas, nu-merosas e complexas a ponto de sua aquisição e assimilação serem, doravante, bastante aleatórias" (2019, p. 183). Nesse contexto de ausência de grandes narrativas, e de grandes memórias organizadoras, "cada indivíduo toma seu próprio caminho e isso resulta em memórias fragmentadas" (2019, p. 184). O autor conclui a reflexão com a máxima: "uma sociedade mal colocada em relação ao tempo é também uma sociedade mal colocada em relação ao sentido que se forma sempre 'na relação do antes e depois, do passado e do futuro'" (2019, p. 186).

Como foi previamente citado, a juventude contemporânea é atravessada por uma miríade de novas influências e contingências inéditas nas sociedades modernas, princi- palmente ocasionadas pelo advento da tecnologia no cotidiano íntimo e social. Sendo uma população em contínuo decréscimo "quer em número, quer em peso relativo, no conjunto total da população" (VIEIRA, FERREIRA \& ROWLAND, 2015, p. 7), os jovens vivem em uma realidade em que, como é apresentado na tese de doutoramento de Jardim (2002), o avanço tecnológico maciço e de forma desenfreada não acompanhou um de-senvolvimento humanitário e ético, gerando "um abismo entre a capacidade inventiva e o aproveitamento generalizado destas novas máquinas" $(2002$, p. 16). Mais ainda, parece existir nas sociedades contemporâneas um imperativo de experiências imediatas. Esse imediatismo tem vindo a ser acompanhado por um interesse acrescido de preservação da memória, das experiências passadas e da busca por territórios de segurança (QUINTE-LA \& GUERRA, 2017).

Surge então a problemática de não haver uma narrativa e estrutura totalizante de sentidos pelas instituições que organize a consciência social, decorrente de diversas cri-ses e do emergente pluralismo de perspectivas e de grupos sociais fragmentados das identidades nacionais, por exemplo. Contudo, nos últimos anos, temos vindo a assistir a um aumento crescente do interesse académico por estas temáticas da memória e da preservação, principalmente no que diz respeito à temática dos arquivos e da música. As-sim, encontramo-nos diante de um caráter polissémico do conceito de memória, dentro dos contributos de Foucault (2014). Então, no que diz respeito ao interesse académico, pugna-se um tipo de pesquisa que extravase o campo restrito da história (QUINTELA \& GUERRA, 2017).

Paralelamente, é reiterado por Candau (2019) que, apesar de numerosas memórias serem destruídas ou desaparecerem, como no caso das grandes memórias, há o surgi-mento de outras "menos expansivas, mais particulares, mas frequentemente abundantes e robustas" (2019, p. 193). São essas as memórias fundamentais para as identidades em re-composição, "que na maior parte do tempo hesitam entre as tentações hegemônicas e o consentimento a um tipo de relativismo memorial" (2019, p. 193). 


\section{Memória e identidade}

Ao elaborar acerca da relação de memória com o passado, presente, futuro e identidade, torna-se propício, antes disso, estruturar a perspectiva desta investigação so-bre o fenômeno do tempo. Para isso, será utilizada a obra de Carlo Rovelli (2018) para sua elaboração. A estrutura do tempo, segundo o autor, é flutuante e, por conta disso, "a distinção entre presente, passado e futuro também se torna flutuante, indeterminada" (2018, p. 73). O acontecer, nessa lógica, se torna difuso, e ele é apenas ordenado pela mente que organiza o fluxo do tempo a partir do passado, em que, ao perceber o acontecimento presente, se coloca em uma organização na formação de contínuos passados. Como explicita o autor, "nossa consciência fundamenta-se na memória e na antecipação" (2018, p. 140). Além disso, a memória também pode ser entendida como uma resposta contrahegemónica, desafiando as visões mainstream (QUINTELA \& GUERRA, 2017).

Justifica-se essa percepção sobre o tempo para iniciar o diálogo acerca da memória, sendo primeiramente estruturado a partir do trabalho de Nascimento e Menan-dro (2005). Como os autores apresentam, a memória pode ser significada como a pro-priedade humana que, ao preservar certos traços de experiências, os permite acesso a partir das lembranças. É reiterado pelos pesquisadores como a função da memória se de-ve à geração do sentido do presente, tanto de um grupo quanto individualmente, e sendo um processo de contínua construção já que ela não é estática, dependendo da "negociação entre as lembranças do sujeito ou grupo e as dos outros grupos ou sujeitos" (2005, p. 8). Isso justifica a premissa de que, caso um grupo mude, suas lembranças também mu-dam, já que o passado deve ser coerente com quem o grupo, enquanto entidade, e seus participantes, são atualmente. Esse fenômeno só é possível com a contínua atualização das lembranças em um repertório consensual, fazendo com que a memória social seja "viva".

A memória se encontra na gênese da formação identitária, não sendo possível, também, dialogar sobre os sentimentos que emergem do sujeito sobre seu futuro sem o correlacionar com sua trajetória autobiográfica. Nesse campo em que diversas influên-cias se afetam, em níveis individuais e coletivos, locais e globais, os elementos memoriais surgem como centrais para compreensão da vivência do indivíduo em sociedade, e das perspectivas que estabelece sobre ela. Como ressalta Wertsch (2002), a memória em ge-ral vai funcionar em um conjunto complexo de representação precisa e de prover conteúdos do passado de forma funcional para o presente e o futuro.

No que tange os aspectos de formação da memória autobiográfica, o trabalho de Draaisma (2004) se torna central. Logo no início de sua obra, o autor reitera como a memória autobiográfica é a companhia mais íntima dos indivíduos, se desenvolvendo ao longo da vida e se transformando de forma gradual, não sendo percebidas essas mudanças. Esse tipo de memória tem seu início a partir da constituição de um "Eu", já que é im-pensável o desenvolvimento de uma autobiografia sem um ator principal, necessitando dessa noção de si. 
Como explora Draaisma (2004), a memória está no centro da experiência de tem-po dos indivíduos, sendo ela quem ativamente elabora no tempo psicológico a percepção sobre o tempo. O autor estabelece que a memória ordena as experiências no tempo, dando profundidade à consciência, e cita o momento do sonhar enquanto dorme um exemplo da quebra da memória, se desfazendo a noção de tempo do sujeito. É também elaborado por Draaisma (2004) como a memória se estabelece cronologicamente a partir de marcações não impostas pelo sujeito, mas sendo impostas a ele. Como expõe o autor: "geralmente elas são puramente individuais, mas podem também ser comuns a uma família ou uma nação toda"5 (2004, p. 217), sendo compostos de acontecimentos cotidianos, situações familiares relevantes, atividades profissionais, etc. Como percebe o pesquisador, elas servem como marcos para ordenar uma trajetória pessoal.

Como apresenta Connerton (1989), toda forma de experiência é baseada em um contexto prévio, garantindo sua inteligibilidade, fazendo com que a mente se estruture a partir de objetos previamente experienciados. É ressaltado pelo autor que "perceber um objeto ou agir sobre ele é o localizar em um sistema de expectativas. $O$ mundo do percipiente, definido em termos de experiência temporal, é um corpo de experiências organizado baseado na lembrança"6 (1989: 6). Ao elaborar acerca de narrativas de vida, Connerton (1989) ressalta como uma narrativa é parte de um conjunto interconectado de narrativas, sendo dessas histórias dos grupos em que os indivíduos constituem sua identidade. Acerca da narrativa individual, ou pessoal como é referida pelo autor, ele estrutura uma lógica similar a de Draaisma (2004), que diz respeito ao passado pessoal. São essas memórias pessoais que surgem de forma significativa na própria descrição, a concepção de si e das próprias potencialidades é intrinsecamente vinculada à percepção das ações passadas.

O lembrar para Connerton (1989) não diz respeito a acessar eventos isolados, mas formar uma narração significativa. O acesso literal à memória dos eventos é raro e não possui grande importância, já que o central do ato de lembrar não é a reprodução, mas a construção de um esquema e de uma narrativa. Essa premissa é ressaltada por Wertsch (2002), que reitera como a representação precisa não é a única função da memória, devendo se utilizar de outros critérios à forma que ela é acessada, o que não elimina a importância do lembrar preciso, mas percebe a memória como "suficientemente comprometida com um projeto de identidade em que a noção de precisão pode ter importância diminuída ou ser sacrificada a serviço de produzir um passado utilizável"7 (2002, p. 32).

Uma diferença central no trabalho de Connerton (1989) para o de Draaisma diz respeito ao quão central são as convenções sociais para a formação da memória. Para Connerton há a necessidade de haver uma convenção de hábitos sociais para a memória ser legitimada socialmente, validando essa performance. É reiterado que toda

\footnotetext{
5 Tradução livre de: "Generally they are purely individual, but they can also be common to a family or an entire nation".

6 Tradução livre de: "To perceive an object or act upon it is to locate it within this system of expectations. The world of the percipient, defined in terms of temporal experience, is an organised body of expectations based on recollection."

7 Tradução livre de: "being sufficiently committed to an identity project that the notion of accuracy may be downplayed or sacrificed in the service of producing a usable past".
} 
lembrança existe em relação com noções que outros também possuem, como: "com pessoas, lugares, datas, palavras, formas de linguagem, ou seja, com toda a vida material e moral das sociedades das quais fazemos parte ou das quais fizemos parte"8 (1989, p. 36). Esses grupos permitem a formação de estruturas em que as memórias são mapeadas e localizadas.

Em relação à esse aspecto da memória social, se torna indispensável abordar o trabalho de Halbwachs (1992). O autor relata como a evocação de lugares e tempos diferentes só é possível pela estrutura do pensamento atual, que, por sua vez, é vinculada aos pensamentos da presente sociedade, fazendo com que a mente seja alinhada com as pressões da sociedade. É explicitado na obra de Halbwachs (1992) como as memórias não são associadas pela sua relação com o tempo, mas a partir dos pensamentos comuns ao grupo com que os indivíduos que as formam mantém relações. Para lembrá-las, torna-se necessário estar na perspectiva do grupo, já que essa memória individual é, pelo menos, parte ou aspecto da memória coletiva.

Para Halbwachs (1992), o grupo ajuda o indivíduo no ato de rememorar, o auxilian-do com informações e estruturas para as lembranças. Nessa construção do passado, o sujeito preserva as memórias de sua vida e, continuamente, as reproduz, sendo nesse fenômeno formado o sentimento de identidade.

Porém, se ressalta a premissa de Wertsch (2002) do perigo de distinguir os proces-sos individuais e coletivos da memória, não devendo isolar os trabalhos de ambas disciplinas. Deve-se compreender a sua relação, já que ambas atuam em conjunto para a constituição da identidade de indivíduos e grupos, tendo função central na elaboração de narrativas e hábitos. Essa construção é central para compreender como o indivíduo se localiza no presente e constitui sua perspectiva sobre o futuro a partir de sua memória e do ato de lembrar.

\section{Música como ferramenta do lembrar}

A relação da música com o sentir e o expressar emoções, de forma intrínseca à identidade do indivíduo, é explorada por uma miríade de facetas com diversas bases epistemológicas. Partindo inicialmente de um campo vinculado a fenômenos fisiológicos, o neurologista Oliver Sacks se torna essencial, principalmente a partir de sua obra Musicophilia. Em relação à emoção, Sacks (2010) revela a história de pacientes em que a atividade musical apresentava ferramentas e mecanismos emocionais que previamente pareciam estar em falta, percebendo completas transformações de pacientes na atividade do cantar.

Ao elaborar sobre os aspectos neurológicos da identidade, Sacks (2010) explica como as redes neurais que compõem o estilo pessoal estão enraizadas de forma tão intrínseca ao sistema nervoso que esses traços nunca são perdidos enquanto há vida mental. Desses traços, os relacionados com sensibilidade, percepção e emoção mu-

8 Tradução livre de: "with persons, places, dates, words, forms of language, that is to say with the whole material and moral life of the societies of which we are part or of which we have been part." 
sical sobrevivem muito além de outras formas de memória, reiterando a importância da intervenção musical em casos de perda de memória. O neurologista ressalta como elas servem para suscitar emoções e associações já perdidas, restabelecendo humores, pensasentos e memórias que, aparentemente, haviam sido perdidos.

A atividade musical está intrínseca no processo de socialização, tanto enquanto formação de grupos, em expressão de categorias sociais, quanto como forma de diálogo com a realidade social para construção da identidade. É salientado por Wisnik (2017) como o som diverge de diversos outros objetos culturais, localizados de forma concreta na realidade e que se apresentam ao imaginário cotidiano pois, o som, "por mais nítido que possa ser, é invisível e impalpável" (2017, p. 30), necessitando de outros sentidos para o identificar, diferentemente do tato e visão, normalmente mais utilizados. O som, então, nas mais diferentes culturas, se define em elementos simbólicos culturais mais profundos, já que ele é tido como "um objeto subjetivo", não se materializando diretamente, mas se fazendo presente com uma enorme precisão. Wisnik reitera que: "As mais diferentes concepções do mundo, do cosmos, que pensam a harmonia entre o visível e o invisível, entre o que se apresenta e o que permanece oculto, se constituem e se organizam através da música" (2017, p. 30).

Quando aplicamos esta questão da memória à música, entra em jogo a problemática da preservação com o intuito de constituir uma herança musical comum, que confira visibilidade às identidades, à partilha comunitária e à preservação de materiais musicais que sejam socialmente desvalorizados (VAN DIJCK, 2006; QUINTELA \& GUERRA, 2017). São múltiplos os campos de exploração, no sentido em que podem ser consideradas memórias: objetos, registos videográficos ou até mesmo sonoros, que são guardados não só pelo amor à criação artística, mas também por estes serem elementos estruturantes que condicionam os projetos identitários individuais e coletivos. Tais considerações refletem-se em diversos eixos, como por exemplo num aumento recente da produção, da exposição e do consumo deste tipo de objetos ou de sonoridades, no sentido em que nos encontramos - frequentemente - perante memorabilia?.

Como na tese de Picchia (2013), o presente trabalho se propõe a "uma reflexão sobre música que não se limite aos aspectos sonoros e técnicos" (2013, p. 13). A perspectiva acerca do trabalho tendo como objeto de pesquisa a música é inspirada na tese de doutorado de Guerra (2013), que percebe como a música "faculta ainda um importante "fundo" sobre o qual podem ser levadas a cabo, performaticamente, estratégias subjetivas de afirmação/aquisição identitária" (2013, p. 61).

Nesse aspecto, se torna propício abordar o trabalho de DeNora (1999), que trata música como uma ferramenta em que atores podem se utilizar na sua contínua construção de si, envolvendo os aspectos emocionais, de memória e biográficos que envolvem nesse processo. A autora percebe como o consumo da música "pode promover um meio para auto-interpretação, para a articulação da auto-imagem e para a adaptação

90 termo, neste caso, é utilizado a partir do trabalho de Sherman (1991), que identifica a memorabilia enquanto objetos materiais afetivos que detém conexões com memórias que o indivíduo desenvolve no decorrer de sua vida. 
de vários estados emocionais associados com o self na vida social"10 (1999, p. 32). Essa é uma prática que diverge da apreciação musical, tendo a música uma função como ferramenta organizadora da subjetividade e do self, de forma pragmática.

Esse papel ativo na atividade musical é reiterado por Hennion (2011), que expressa como os indivíduos são ativos e produtores em relação às obras, tendo capacidade de "transformar e criar novas sensibilidades, em vez de somente reproduzir silenciosamente uma ordem existente" (2011, p. 256). O pesquisador elabora como a música sempre se transforma no contato com o público, por depender de sua escuta, sendo o degustar também uma performance, sendo "algo que age, que engaja, que transforma, que faz sentir" (2011, p. 260). É também explorado pelo autor como o gosto, enquanto trabalho, também requer um corpo, que o degusta, e que não é um dado natural, sendo resultado da atividade, que treina, ao longo prazo, o "caráter ativo da colocação de si próprio em condição no momento de degustar" (2011, p. 262).

Se atendo a essas noções de construção e de processo ativo musical, Hennion (2011) estabelece como a música depende de uma produção coletiva a longo prazo, gerando um "ouvido" específico. Isso é percebido desde o "estabelecimento mais geral de um quadro da atenção (escutar a música pela música) ao hábito mais local e pessoal de escutar tal ou tal peça no momento e lugar em que quisermos" (2011, p. 270).

Ao apresentar o dossiê de uma edição da revista Sociedade e Cultura, Fernandes et al (2008) debatem como as experiências musicais "constituem eventos que conjugam as sensibilidades do indivíduo e da coletividade, compondo um tecido social denso de significado" (2008, p. 155). São exatamente a partir dessas experiências que são desenvolvidos os entendimentos acerca da realidade que rodeia os indivíduos, afetando seu comportamento e sua visão de mundo. De acordo com os autores, a atividade musical envolve diversos sentidos, por estar inserida em diversas práticas, como "pela dança, pela memória, pela apreciação, pelos estímulos à imaginação" (2008, p. 156), sendo extremamente democrática por estar disponível a todos. O fenômeno musical, então, com uma ampla margem de significados, "ocorre de diferentes formas e compreende, além do som, ideias e comportamentos" (2008, p. 156).

A relação da atividade musical com a memória é reiterada por Reily (2014), que constata que o fazer musical não seria possível sem a memória, já que ela é utilizada em múltiplas instâncias na composição, como em memórias iniciais, envolvendo "lembrar a melodia, o ritmo e o texto da música, informação armazenada em nosso cérebro" (2014, p. 1), e de memórias musculares, que contemplam a "emissão dos sons, tais como o uso do aparato vocal, da respiração e demais órgãos corporais envolvidos no canto" (2014, p. 1). É também reiterado como, no momento do canto, são evocadas memórias que dizem respeito ao contexto, como experiências passadas que a música foi cantada pelo sujeito ou que ele ouviu outra pessoa cantar. Como ressalta a autora: "a memória, então, é um espaço em que as esferas biológicas e socioculturais do ser humano se encontram" (2014, p. 2).

10 Tradução livre da passagem: "may provide a means for self-interpretation, for the articulation of self-image and for the adaptation of various emotional states associated with the self in social life". 
É reiterado por Reily (2014) como a memória musical envolve diversos elementos que compõem o complexo em que ela foi inicialmente vivida, podendo listar, no caso da performance musical, características como: "quem estava presente no evento da performance; como estas pessoas se comportaram; onde ocorreu; as características do local; o posicionamento da música em relação às outras atividades do evento; a sua temporalidade" (2014: 6), entre diversas outras possibilidades. Essas memórias são categorizadas e armazenadas ora com precisão, ora de forma paradigmática, vindo a se integrar a mapas neuronais, que serão mobilizados em conjunto com outros elementos que compõem o ato de lembrar. Partindo dessa premissa, Reily lembra como basicamente todas as pessoas em nossa sociedade já devem ter vivenciado a experiência de flashes de lembranças ao ouvir uma música, principalmente de episódios de grande impacto afetivo, como: "a peça que tocamos no nosso primeiro recital de piano; a música que estava tocando na primeira vez em que dançamos com o/a namorado/a; a música no primeiro disco que compramos etc" (2014, p. 7).

É explorado por DeNora (1999) como a música surge como um dos diversos dispositivos de recuperação da memória (o que, de acordo com a autora, ocorre simultaneamente com a construção da memória). Ela expressa: "música pode ser usada como um dispositivo para o processo reflexivo de lembrar/construir quem o indivíduo é, uma tecnologia para contar a aparente história contínua de quem o sujeito é"11 (1999, p. 45).

A importância da emoção em relação à memória é ressaltado no estudo de Justel, O'Connor \& Rubinstein (2015) que ressaltam que, apesar da capacidade de memória declinar ao longo da vida, o efeito modulador da emoção na memória não necessariamente se encontra afetado. Em seu estudo com adultos mais velhos, os autores utilizaram música como estímulo para elaboração da memória, e foi percebido como, quando envolvida a emoção, a elaboração da memória tinha maior efeito que em cenários neutros.

O fenômeno do lembrar nas próprias canções é explorado por Nascimento e Menandro (2005) ao analisar diversas canções brasileiras que elaboravam acerca do tema das memórias de infância. É ressaltado a presença da imagem da infância feliz, um tempo em que "estão fortemente associados aspectos lúdicos, a infância recordada também se refere a uma potencialidade" (2005, p. 21), estando repleta de descobertas e sonhos, que foram declinando e sendo perdidos no decorrer da vida. Como os autores elaboram, esse discurso não é particularizado, e é expresso dessa forma exatamente por partir do reconhecimento dos ouvintes com esse ideal, havendo conteúdos comuns das canções que permitem essa esquematização acerca do imaginário relatado.

Como é ressaltado por Nascimento e Menandro (2005), esse olhar para a infância com saudade, e dos elementos comuns nesse olhar, permitem a formação de um grupo, já que há lembranças comuns coerentes na formação desse passado. Deixa-se de ter importância o critério de veracidade, já que o que sustenta esse fenômeno é o de que "a memória de cada compositor concorde com a de seus pares e sustente um agrupamento de lembranças que necessita ser coerente" (2005, p. 22).

11 Tradução livre do trecho: "Music can be used as a device for the reflexive process of remember-ing/constructing who one is, a technology for spinning the apparently 'continuous' tale of who one 'is'". 
Em relação ao objeto de análise proposto, que seria a experiência musical do amador, Hennion (2011) reitera como devem-se considerar "as ligações, os gostos, os modos de fazer e os prazeres" (2011, p. 261) desse público, sendo ela uma competência elaborada e capaz de autocrítica, sem ser "apenas o jogo passivo da diferenciação social" (2011, p. 261). É reiterado também como há uma importância social e político nessa forma de aproximação e da relação consigo, com os outros e com o mundo que o sujeito amador estabelece, e a partir dessas conexões, pode-se "contribuir de maneira mais geral para uma melhor compreensão das modalidades heterogêneas de nossas ligações" (2011, p. 261).

Permite-se, então, compreender como a atividade musical está intrínseca na atividade da memória e do lembrar, e das vinculações de ambas com a formação de uma identidade social e própria do indivíduo. A emoção no lembrar pela música toma um lugar central no ato de lembrar, dando sentido ao presente a partir da evocação das memórias afetivas, sendo elas mais significativas.

Surge então a vinculação central entre a atividade musical e o lembrar como ação de dar sentido ao presente. A consequência desse fenômeno é o refletir acerca do futuro em uma nova perspectiva sobre o agora, permitindo que a atividade musical esteja em um local privilegiado na formação imaginária sobre a história e o trajeto de vida futuro.

\section{O lembrar para construção de um futuro perdido}

A ideia passada trazida pelo futuro, que previamente se realizava em uma esperança de uma realidade diferente, de uma vida melhor, de resolução dos conflitos presentes, se apresenta minada pelo resultado de diversas dificuldades e violências do presente. Pela comunicação virtual, há uma maior conexão dos indivíduos jovens com os acontecimentos do mundo, além de estudos e previsões relacionados a esses fenômenos, gerando maior descrença acerca do futuro de sua sociedade e da humanidade como um todo.

Esse fenômeno impacta diretamente a percepção destes indivíduos jovens sobre o presente, gerando outros movimentos percebíveis atualmente, como a diminuição da natalidade, que possui como um grande fator a desesperança do futuro do planeta. Além disso, é possível também perceber um maior grau de ansiedade e adoecimento por parte dessa população, tendo que lidar com informações e situações inéditas para uma juventude.

Apesar desse fenômeno, e do respaldo dessas informações na realidade, surge a necessidade de atitudes e hábitos que redimensionem esse olhar, reiterando os aspectos positivos e sólidos da história de vida e do presente desses indivíduos. Um dos fenômenos centrais nesse processo é o da memória, que, por não possuir um conteúdo objetivo, constrói o imaginário de um passado, permitindo reconfigurar a percepção do presente e do futuro a partir da narrativa desenvolvida. Nesse processo, a memória age muito mais em relação ao futuro do que ao passado, por conta de sua função central ser dar sentido ao presente e ao futuro na configuração desse passado imaginário. 
A atividade musical está intrinsecamente ligada à formação da identidade social e individual. Isso pode ser comprovado desde a vinculação de grupos sociais, com ideais similares, identificados pelos gostos musicais, até a vinculações de lembranças a partir de traços musicais associados à elas, que vão vir a constituir parte intrínseca da identidade do indivíduo. Esse fenômeno é reiterado a partir de intervenções de musicoterapia em pacientes que possuem o mal de Alzheimer ${ }^{12}$, recuperando diversas áreas da cognição, representando o quanto interligadas e importantes são as memórias musicais.

Como apresenta Wertsch (2002), há a diferença do lembrar e do reexperienciar, em que, pelo lembrar, há uma separação do indivíduo ou grupo do evento em si, enquanto no ato de reexperenciar há uma imersão do evento no passado, dissolvendo essa distância, a atividade musical permite esse ato de reexperenciar, possibilitando esse contato mais sensível e próximo com eventos passados e com a narrativa que o sujeito estrutura com sua narrativa de vida, permitindo a elaboração de uma estrutura de consciência e sentido.

Propõe-se que esse contato com o passado, a partir do questionamento da distinção entre passado, presente e futuro, havendo uma relação intrínseca da vivência de todos esses momentos vivenciados pelo sujeito, e de como esse lembrar do passado é essencial para o desenvolvimento de uma consciência e de um sentido em relação ao futuro. A falta de estrutura proporcionada pelas grandes narrativas sociais e históricas surge como possibilidade de surgimento de uma pluralidade na criação de sentido e de narrativas individuais que, por mais que ainda estejam vinculadas a estruturas memoriais sociais, e em um espaço de contínua negociação, podem ser fortalecidas a partir da construção de uma narrativa autobiográfica pela atividade musical.

Justifica-se, então, a possibilidade de intervir a partir da atividade musical em relação à formação e elaboração de memórias, principalmente no que tange à construção da identidade dos sujeitos. Nesse caminho, se traça a linha de raciocínio de utilizar a ativida-de musical, principalmente relacionada às músicas que o indivíduo vincula com afeto e com suas crenças centrais, para a criação de memórias que auxiliem na construção de sentido sobre o presente e o futuro. Foca-se em um indivíduo ativo nesse processo, que dialoga com os elementos sociais que o circunscrevem, com o seu processo histórico e ontológico, e com os objetos musicais que permitem suas significações e experiências próprias.

\section{Considerações finais}

A presente reflexão buscou elaborar acerca da possibilidade de desenvolvimento de pesquisas no campo da memória a partir da intersecção dos temas de atividade musical, memória e sentido. Esses campos possuem diversos fenômenos intrínsecos entre si, sendo um afetado pelo outro continuamente na vivência cotidiana individual e coletiva. Defende-se que uma resposta possível acerca da crise de sentido vivenciada pela socie-dade é pela

12 Doença neurológica degenerativa que possui como resultado, por exemplo, a disfunção neural, atrofias de regiões neurais e demência. Maiores informações sobre a doença e sua correlação com intervenções musicais podem ser acessadas no trabalho de Jacobsen et al (2015). 
atividade musical, que permite, a partir do ato de lembrar e reexperienciar, estruturar uma narrativa autobiográfica coerente, possibilitando a elaboração de sentido sobre o futuro. 0 reconhecimento, então, da importância estratégica da música na construção identitária, e o reconhecimento desse fato por parte da própria sociedade, tem operado uma crescente mercantilização da música usada no marketing e na venda de determinadas marcas, na comercialização de determinados produtos, cujos mais emblemáticos serão as telecomunicações e as bebidas numa aproximação clara à perspectiva de Marcuse.

De acordo com Hall (1996), as identidades são posições que os indivíduos ocupam no discurso e que os ligam a estruturas de significado e a processos sociais. Por outras palavras, as identidades são entendidas como recursos simbólicos que as pessoas utilizam de diferentes formas a fim de se posicionarem relativamente a processos sociais e ideológicos e a grupos. No fundo, a identidade constitui um repertório simbólico partilhado, através do qual os indivíduos constroem uma vivência de similaridades ou de diferencia-ções.

As preferências musicais de um sujeito podem expressar fatos centrais da identidade que elege para si mesmo, tanto pelo que se aproxima quanto pelo que possui repulsa, além de demonstrar suas identificações com grupos sociais, e momentos que seu ato de lembrar está vinculado. Esse consumo simbólico está intrinsecamente vinculado ao significado social e subjetivo que o sujeito possui com as obras em que se vincula, e esse ato de consumo, que é vinculado com o ato de lembrar, pode se dar a partir de diversas manifestações ritualísticas, como o cantar e o dançar as canções pelas quais possui mais afeto, além da aquisição de outras formas materiais que vinculam com esses afetos, como discos, mantendo uma relação contínua de elaboração desse self vinculado com a atividade musical.

As atividades musicais revelaram-se fundamentais para a estruturação de um self, que virá a permear e realizar trocas no mundo social. Podendo atuar como expressão emocional, a música se insere como um dos grandes alicerces para a criação de marcações temporais memoriais, que poderão vir a ser utilizadas para uma reconstrução afetiva de experiência passada. Esse ato é central para a construção de uma narrativa autobiográfica, que por sua vez, esse passado coerente, se torna central para a perspectiva e significação de um futuro coerente.

Assim, reiteramos a necessidade do desenvolvimento de mais pesquisas que busquem o diálogo entre os campos propostos, sendo esse movimento possível a partir de diversas óticas, tendo como exemplo a Psicologia, a Sociologia, a Antropologia e a Musicoterapia, área central para a utilização dos conhecimentos musicais para intervenção na realidade. Espera-se que as produções que visem essa intersecção possibilitem a elucidação de diversos fenômenos contemporâneos que dizem respeito à memória e ao desenvolvimento de sentido. 


\section{Referências}

AUGÉ, Marc. Para onde foi o futuro?. São Paulo: Papiro, 2012

BERGER, Peter L., LUCKMANN, Thomas. Modernity, pluralism and the crisis of meaning. Gütersloh: Bertelsmann Foundation Publishers, 1995.

CANDAU. Joël. Memória e Identidade. São Paulo: Contexto, 2019.

CONNERTON, Paul. How societies remember. Cambridge University Press, 1989.

DENORA, Tia. Music as a technology of the self. Poetics, 27, 1, 31-56,1999.

DRAAISMA, Douwe. Why life speeds up as you get older: How memory shapes our past. Cambridge University Press, 2004.

FERNANDES, Adriana et al. Música, sociabilidade e memória. Sociedade e cultura, v. 11, n. 2, p. $155-157,2008$.

FOUCAULT, Michel. A Arqueologia do Saber. Lisboa: Edições 70, 2014.

GUERRA, Paula. A instável leveza do rock: gênese, dinâmica e consolidação do rock alternativo em Portugal (1980-2010). Porto: Afrontamento, 2013.

HALBWACHS, Maurice. On collective memory. University of Chicago Press, 1992.

HALL, Stuart. Who needs identity. Questions of cultural identity, 16(2), 1-17, 1996.

HENNION, Antoine. Pragmática do gosto. Desigualdade \& Diversidade-Revista de Ciências Sociais da PUC-Rio, 8, 253-277, 2011.

JACOBSEN, Jörn-Henrik et al. Why musical memory can be preserved in advanced Alzheimer's disease. Brain, v. 138, n. 8, p. 2438-2450, 2015.

JARDIM, Maria Helena de Agrela Gonçalves. Juventude! Que futuro neste mundo imprevisível e de incertezas? Ansiosa!?! Depressiva!?!... Como prevenir?. Tese de Doutorado. Universidad de Extremadura. 2002.

JUSTEL, Nadia; O'CONOR, JAIME; RUBINSTEIN, Wanda. Modulación de la memoria emocional a través de la música en adultos mayores: Un estudio preliminar. Interdisciplinaria, v. 32, n. 2, p. 247-259, 2015. 
NASCIMENTO, Adriano Roberto Afonso; MENANDRO, Paulo Rogério Meira. Memória social e saudade: especificidades e possibilidades de articulação na análise psicossocial de recordações. Memorandum, v. 8, p. 5-19, 2005.

NASCIMENTO, A. R. A. do; MENANDRO, P. R. M. Reinações de menino: a memória saudosa da infância na música popular brasileira. Memorandum: Memória e História em Psicologia, [S. I.], v. 9, p. 9-27, 2005. Disponível em: https://periodicos.ufmg.br/ index.php/memorandum/article/view/6743. Acesso em: 23 nov. 2020.

PICCHIA, Paulo Menotti Del. Por que eles ainda gravam? Discos e artistas em ação. Tese de Doutorado. Universidade de São Paulo. 2013.

QUINTELA, Pedro; GUERRA, Paula. Ciências sociais, arquivos e memórias: considerações a propósito das culturas musicais urbanas contemporâneas. Sociologia, v. 33, p. 155-181, 2017.

REILY, Suzel Ana. "A música e a prática da memória - uma abordagem etnomusicológica". Salvador: Música e Cultura, 9, 2014.

ROVELLI, Carlo. A ordem do tempo. Rio de Janeiro: Companhia das Letras, 2018.

SACKS, Oliver. Musicophilia: Tales of music and the brain. Vintage Canada, 2010.

SHERMAN, Edmund. Reminiscentia: Cherished objects as memorabilia in late-life reminiscence. The International Journal of Aging and Human Development, v. 33, n. 2, p. 89-100, 1991.

VAN DIJCK, José. Record and hold: Popular music between personal and collective memory. Critical Studies in Media Communication, v. 23, n. 5, p. 357-374, 2006.

VIEIRA, Maria Manuel; FERREIRA, Vitor Sérgio; ROWLAND, Jussara. Retrato da Juventude em Portugal: traços e tendências nos censos de 2001 e 2011. Revista de Estudos Demográficos, v. 54, p. 5-25, 2015.

WERTSCH, James V. Voices of collective remembering. Cambridge University Press, 2002.

WISNIK, José Miguel. (2017). O som e o sentido: uma outra história das músicas. São Paulo: Editora Companhia das Letras, 2017. 